\title{
Optimization of Heat Source Temperature for Single and Double Effect Vapor Absorption Refrigeration System
}

\author{
M. Galal*, E. Elgendy, S. Shabaan \\ * Mechanical Engineering Department (Mechatronics), College of Engineering \& \\ Technology at Arab Academy for Science, Technology \& Maritime Transport, Cairo, \\ Egypt.
}

\begin{abstract}
Studying the absorption refrigeration systems is very important in recent years because the primary energy that is used in an absorption system can be either heat available from a residual source or even a renewable one. Therefore, these systems not only use the energy that would be rejected to the environment, but they also avoid the consumption of fossil fuel or electrical energies. In this study, the energy and exergy analysis of both single \& double effect water-LiBr absorption system is presented. The work is carried out for air conditioning applications. The investigated performance parameters are the coefficient of performance and the exergy efficiency. The effect of the operating temperatures on such parameters is included. An analysis of the individual components is also presented. The most noticeable effect is observed for the case of the exergy efficiency for the absorber and the generator. The obtained results allow the identification of the parameters that may influence the exergy efficiency of the adiabatic absorption system. A thermodynamic optimization analysis of both single \& double effect $\mathrm{LiBr}-\mathrm{H}_{2} \mathrm{O}$ absorption cooling system of fixed cooling capacity is conducted based on the first and the second laws of thermodynamics. Mathematical models that derived from the thermodynamics theory are employed in the engineering equation solver (EES) software to perform the calculations. It is observed that the optimum heat source temperature decreases with the evaporator temperature and increases with the condenser temperature. Hence it is feasible to find out an optimum heat source temperature for various condenser-evaporator temperatures. Evaluation of the optimized system is conducted owing to the fact that the optimum heat source temperature corresponding to the maximum $\mathrm{COP}$ and the minimum exergy destruction is not identical.
\end{abstract}

Key-Words: - Absorption system, cooling, exergy, optimization, EES 


\section{Nomenclature}

$\begin{array}{ll}\text { LiBr- } \mathbf{H}_{2} \mathbf{O} & \text { water lithium bromide } \\ \text { COP } & \text { Coefficient of performance [-] } \\ \text { ECOP } & \text { Exergetic coefficient of performance }[-] \\ \text { EES } & \text { Engineering equation solver software } \\ \text { VARS } & \text { Vapor absorption refrigeration system } \\ \text { SVARS } & \text { Single Vapor absorption refrigeration system } \\ \text { CFC } & \text { Chlorofluorocarbons chemical } \\ \text { DVARS } & \text { Double Vapor absorption refrigeration system } \\ \text { e } & \text { Specific exergy of pure substance } \\ \mathbf{E}_{\mathbf{d}} & \text { Exergy destruction } \\ \mathbf{W}_{\mathbf{p}} & \text { Pump work }[\mathrm{J}] \\ \mathbf{T} & \text { Temperature }\left[{ }^{\circ} \mathrm{C}\right] \\ \mathbf{T}_{\text {c.m }} & \text { Cooling medium temperature }\left[{ }^{\circ} \mathrm{C}\right] \\ \mathbf{T}_{\text {app }} & \text { Application temperature }[\cdot \mathrm{C}] \\ \mathbf{1} & \end{array}$

\begin{tabular}{|c|c|c|}
\hline$m$ & Mass flow rate of substance $[\mathrm{kg}$ & $\mathrm{g} / \mathrm{s}]$ \\
\hline $\mathbf{h}$ & Substance enthalpy & \\
\hline$Q_{G}$ & Generator heat energy $[\mathrm{kW}]$ & \\
\hline$Q_{c}$ & Condenser heat energy $[\mathrm{kW}]$ & \\
\hline$Q_{A}$ & Absorber heat energy $[\mathrm{kW}]$ & \\
\hline$Q_{E}$ & Evaporator cooling load [kW] & \\
\hline$Q_{L P G}$ & Low pressure generator heat energy & {$[\mathrm{kW}]$} \\
\hline$Q_{H P G}$ & High pressure generator heat energy & {$[\mathrm{kW}]$} \\
\hline$E_{D, E}$ & Evaporator exergy destruction rate & {$[\mathrm{kW}]$} \\
\hline$E_{D, A}$ & Absorber exergy destruction rate & {$[\mathrm{kW}]$} \\
\hline$E_{D, C}$ & Condenser exergy destruction & {$[\mathrm{kW}]$} \\
\hline$E_{D, G}$ & Generator exergy destruction & {$[\mathrm{kW}]$} \\
\hline$E_{D, E X}$ & Expansion valve exergy destruction & $\mathrm{n}[\mathrm{kW}]$ \\
\hline$\varepsilon_{\mathrm{HE}}$ & Heat exchanger effectiveness [\%] & \\
\hline
\end{tabular}

\section{Introduction}

There is a growing need for building air conditioning industry all over the world. Researches on vapor absorption refrigeration system (VARS) have been increased by scientists as these systems harness non-conventional energy sources such as solar, biomass, geothermal etc. In addition, VARS causes no environmental hazardous such as global warming, ozone layer depletion because the working fluids used in this system do not contain chlorofluorocarbons chemical (CFC) which is being used in conventional vapor compression chillers [1]. For cooling and refrigeration over $0^{\circ} \mathrm{C}$ temperature of the evaporator, absorption chillers using $\mathrm{LiBr}-\mathrm{H}_{2} \mathrm{O}$ solution offer very good efficiency than the other solutions. However, there is a risk of salt crystal formation, called solution crystallization, which happens when there is low ambient temperature or high absorber temperature, and air leak into machine.

The COP of an absorption cycle depends on three external temperatures; ambient (cooling medium), generation (heat source), and evaporation (application) temperatures. The triple effect cycle has the best COP among the half effect, the single effect, and the double effect cycles. The half effect cycles has the lowest COP while the single effect cycle presents better COP than the half one. However, the double effect cycle has better COP than the single one. The double and the single effect absorption cycles have more commercial use than the half one and triple one [2,3]. The air cooled double effect systems are better than the single one because they are more efficient, flexible, without cooling tower and independent on water.

The same driving heat source of the single effect cycle produces twice the refrigerant vapor in the double effect cycle and thus two vapor generators are needed. Among the different configurations of the double effect cycles, the most common ones are in parallel and in series cycle layouts. In series means that without dividing into two streams the entire flow 
goes through both generators. In parallel cycle the solution flow going to the high pressure generator does not go to the lower pressure generator. The solution stream split among both. The in parallel layouts have higher COP; however in series layouts are better in the cooling capacity than the in parallel layouts [4]

Florides et al. [5] observed that the total equivalent warming impact of the conventional R22 compression chiller is 1.2 times higher than $\mathrm{LiBr}-\mathrm{H}_{2} \mathrm{O}$ VARS. It is observed that the $\mathrm{COP}$ of the $\mathrm{LiBr}-\mathrm{H}_{2} \mathrm{O}$ VARS is quite lower compared to the compression chiller [6]. Therefore, it is necessity to optimize the performance of the VARS in commercial cooling applications. Detailed thermodynamic analysis of $\mathrm{LiBr}-\mathrm{H}_{2} \mathrm{O}$ VARS with the help of the first and second laws of thermodynamics is very important because heat of mixing of fluids in absorber and generator [7].

Myat et al. [8] developed a numerical model with the help of the genetic algorithm to predict the performance of the $\mathrm{LiBr}-\mathrm{H}_{2} \mathrm{O}$ VARS. They concluded that the maximum entropy generation occurred in the generator followed by the evaporator, the absorber, and the condenser. It is found that around $90 \%$ of the entropy generation occurred in the absorber, the generator, and the evaporator [9]. Meanwhile, the heat load and exergy destruction in the evaporator and the condenser is less compared to that of the absorber and the generator because the heat of mixing in the solution is not present in the evaporator and the condenser [6].

It is observed [10] that for better performance of absorption chillier, the first priority must be given to the optimization of evaporator while absorber should be considered as second. Although, it is also found that absorber, generator and evaporator are the three components having highest exergy loss rate [11]. It is also reported that around $87 \%$ of exergy losses in system occur in the generator and absorber [12].

Gutiérrez-urueta et al. [13] observed that absorber has the lowest value of exergetic efficiency among all the components of the system. Therefore, better performance of the system absorber needs to be optimized. It is also found that for both single and double effect $\mathrm{LiBr}-\mathrm{H}_{2} \mathrm{O}$ VARS, the highest irreversibility takes place in the absorber followed by the condenser, the evaporator and the solution heat exchanger [14]. It is also evaluated that for each condenser and evaporator temperature combination there is an optimum generator temperature where exergy loss of the system is minimum and different optimized value of generator temperature for optimized COP and exergetic efficiency. [15].

Macros et al. [16] developed a new method in which solution concentration has been selected for optimizing parameters to optimize the $\mathrm{COP}$ of $\mathrm{LiBr}-\mathrm{H}_{2} \mathrm{O}$ VARS. However, it is not possible to control the solution concentration directly because it depends upon the system temperature. Thermodynamic analysis and optimization is the main method for improving efficiency of an absorption cycle.

In the present work first law and second law based thermodynamic analysis has been adopted to optimize the single and double VARS. A realistic comparison of the first and second law perspectives have been evaluated to provide direction towards optimum system design. The focus is on recognition of optimum heat source temperature for both the energy and exergy perspective as well as minimum generator temperature required to operate system have been also evaluated. COP and exergy destruction rate of system are 
selected as objective parameters and influence of condenser and evaporator temperature upon optimum generator temperature has been also evaluated.

\section{Absorption system description}

2.1 Single effect vapor absorption refrigeration system (SVARS).

A single effect absorption refrigeration system is the simplest form of absorption refrigeration system. It consists of a generator, an absorber, a condenser, an evaporator, a heat exchanger, a pump and two expansion valves as shown in Fig. 1.

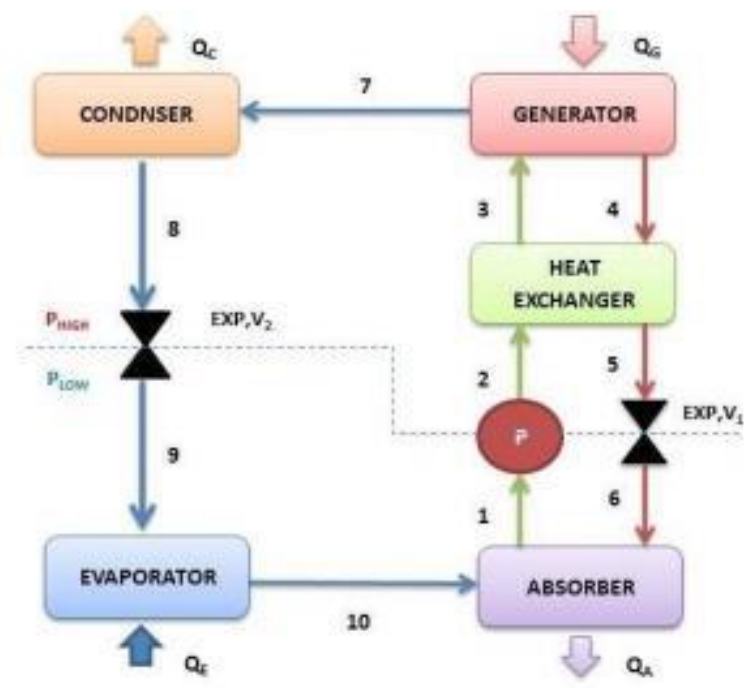

Fig .1 Single effect vapor absorption refrigeration system.

The process starts when the strong solution leaves the absorber at state 1 to enter the pump. In the pump, the pressure of the strong solution increases to the generator pressure and it leaves at state 2 . The strong solution then enters the heat exchanger at state 2 , where it gains heat from the returning weak solution to leave at a slightly higher temperature at state 3 . The strong solution at state 3 then enters the generator, where it gains heat from the heat source and starts boiling, hence the refrigerant vaporizes before the absorbent and leaves at state 7 . Once the refrigerant vaporizes from the strong solution, what is left in the generator is a weak solution which leaves at state 4 . The vaporized refrigerant leaving at state 7 later enters the condenser, where it rejects heat to the surroundings to leave at a relatively lower temperature at state 8 .

The precooled refrigerant then enters the expansion valve, where its pressure drops to leave at state 9 as a vapor-heavy saturated mixture. This vapor-heavy saturated mixture later enters the evaporator, where it gains heat from the cooled space to leave at state 10 . The refrigerant leaving at state 10 then enters the absorber. The weak solution exiting the generator at state 4 enters the heat recovery heat exchanger, where it loses heat to the incoming strong solution to leave at state 5 at comparatively lower temperature. The weak solution at state 5 then enters the expansion valve, where its pressure drops to the absorber pressure before entering the absorber at state 6 . In the absorber, the weak solution and the refrigerant mixes together and release heat to leave as a strong solution at state 1 . 


\subsection{Double effect vapor absorption refrigeration system (DVARS).}

The schematic diagram of a double effect parallel flow absorption system is given in Figure 2. The solution that is pumped from the pump no. 1 is heated in the heat exchanger no. 2 and firstly enters the low pressure generator which is heated by the condenser no.1, after that the liquid solution is pumped with pump no.2 to the heat exchanger no. 1 and then enters the high pressure generator. The vapor taken from the high pressure generator, condensates in the condenser no.1 and some of the heat energy is transferred into the low pressure generator. The liquid enters condenser no.2 and mixes with the vapor coming from the low pressure generator. After that the liquid transferred from the expansion valve no.4 evaporates in the evaporator to obtain cooling.

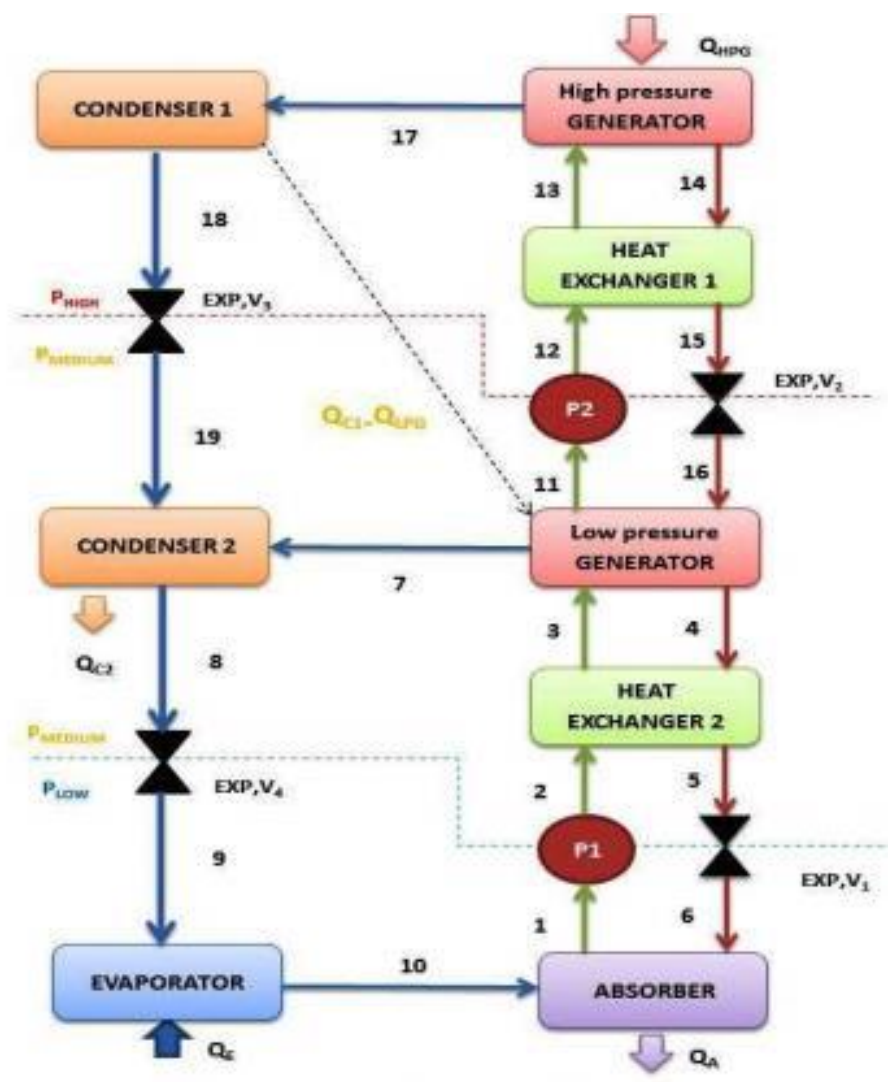

Fig .2 Double effect vapor absorption refrigeration system.

\section{Mathematical model assumptions.}

These assumptions are utilized in the analysis of the cycle:-

- The cycle is at steady state.

- Ambient temperature and pressure conditions are $25^{\circ} \mathrm{C}$ and $100 \mathrm{KPa}$ respectively.

- Pumps and pressure reducing valves process is adiabatic.

- Refrigerant leaving the condenser is saturated liquid at condenser pressure. 
- Solution leaving the generators and the absorber are assumed to be saturated in equilibrium conditions at its respective temperature and pressure.

- Refrigerant leaving the evaporator is saturated vapor at evaporator pressure.

- Direct heat transfer from the components to the surroundings is negligible.

- No pressure changes except through flow restrictors and pump.

- Temperature difference between high-temperature condenser and low temperature generator is $5 \mathrm{~K}$.

- Solution heat exchangers have same effectiveness (70\%).

- Upper loop solution flow rate is selected such that upper condenser heat exactly matches lower generator heat requirement.

- Vapor leaving both generators is at equilibrium temperature of entering solution stream.

\section{Governing equations}

In this study the thermodynamic analysis of the cycles which are given in fig. 1 and 2 are done using the simulation software EES [17]. The thermodynamic and the mathematical modeling are explained by the equations given in Table 1 for the SVARS and Tables 2 for the DVARS.

Exergy analysis is a combination of first and second law of thermodynamics and it indicates the maximum potential work of the system with respect to its surroundings [18]. Specific exergy of pure substance is given by [1].

$$
e=\left(h-h_{o}\right)-T_{o}\left(s-s_{o}\right)
$$

For non-ideal system such as LiBr-H2O VARS only physical exergy is considered while chemical exergy is neglected. Rate of exergy destruction in any component undergoing a steady flow process can be given by [2].

$$
E_{\text {destruction }}=\sum m_{\text {in }} e_{\text {in }}-\sum m_{\text {out }} e_{\text {out }}-\left[\sum Q\left(1-\frac{T_{o}}{T}\right)\right] \pm W_{p}
$$

Table 1. SVARS Analysis.

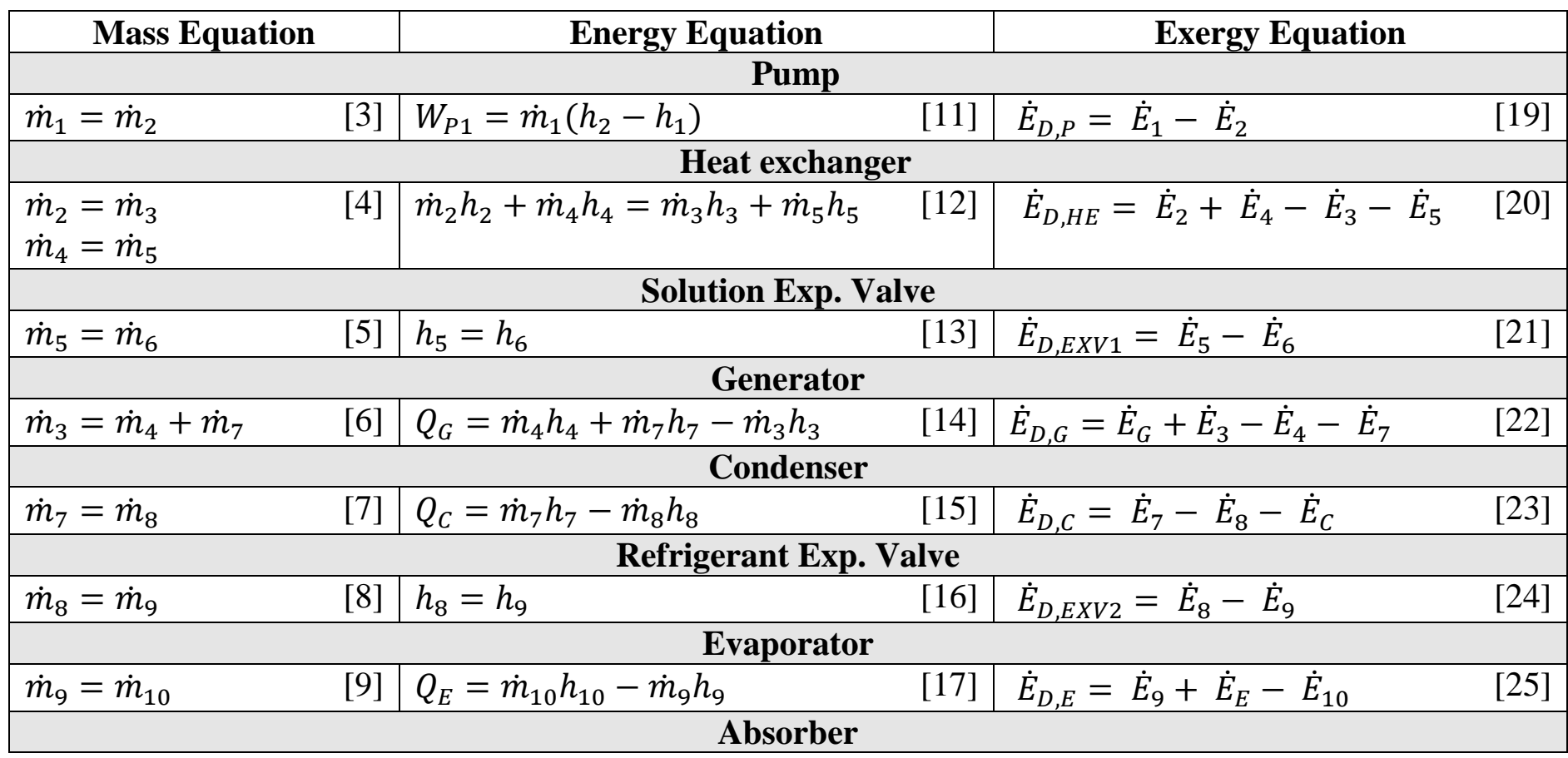




\begin{tabular}{|c|ll|l|ll|}
\hline$\dot{m}_{1}=\dot{m}_{10}+\dot{m}_{6}$ & {$[10]$} & $Q_{A}=\dot{m}_{10} h_{10}+\dot{m}_{6} h_{6}-\dot{m}_{1} h_{1}$ & {$[18]$} & $\dot{E}_{D, A}=\dot{E}_{10}+\dot{E}_{6}-\dot{E}_{A}-\dot{E}_{1}$ & {$[26]$} \\
\hline & Overall cycle \\
& $C O P=\dot{Q}_{E} /\left(W_{P, \text { tot }}+\dot{Q}_{G}\right)$ & {$[27]$} & $E C O P=\dot{E}_{E} /\left(W_{P, \text { tot }}+\dot{E}_{G}\right)$ & {$[28]$} \\
\hline
\end{tabular}

Table 2. DVARS Analysis.

\begin{tabular}{|c|c|c|c|c|}
\hline Mass Equation & & Energy Equation & Exergy Equation & \\
\hline & & Low pressure Pump & & \\
\hline$\dot{m}_{1}=\dot{m}_{2}$ & [29] & $W_{P 1}=\dot{m}_{1}\left(h_{2}-h_{1}\right)$ & $\dot{E}_{D, P}=\dot{E}_{1}-\dot{E}_{2}$ & [57] \\
\hline & & Heat exchanger 2 & & \\
\hline $\begin{array}{l}\dot{m}_{2}=\dot{m}_{3} \\
\dot{m}_{4}=\dot{m}_{5}\end{array}$ & {$[30]$} & $\dot{m}_{2} h_{2}+\dot{m}_{4} h_{4}=\dot{m}_{3} h_{3}+\dot{m}_{5} h_{5}$ & $\begin{aligned} \dot{E}_{D, H E 2}=\dot{E}_{2} & +\dot{E}_{4}-\dot{E}_{3} \\
& -\dot{E}_{5}\end{aligned}$ & [58] \\
\hline & & Solution Exp. Valve 1 & & \\
\hline$\dot{m}_{5}=\dot{m}_{6}$ & [31] & $h_{5}=h_{6}$ & $\dot{E}_{D, E X V 1}=\dot{E}_{5}-\dot{E}_{6}$ & [59] \\
\hline & & Low pressure generator & & \\
\hline $\begin{array}{l}\dot{m}_{3}+\dot{m}_{16} \\
=\dot{m}_{4}+\dot{m}_{11}\end{array}$ & [32] & $\begin{array}{l}Q_{L P G}=\dot{m}_{4} h_{4}+\dot{m}_{11} h_{11}-\dot{m}_{3} h_{3}- \\
\dot{m}_{16} h_{16}\end{array}$ & $\begin{array}{l}\dot{E}_{D, L P G}=\dot{E}_{C 1}+\dot{E}_{3}+\dot{E}_{16}- \\
\dot{E}_{11}-\dot{E}_{4}\end{array}$ & [60] \\
\hline & & Condenser 1 & & \\
\hline$\dot{m}_{17}=\dot{m}_{18}$ & [33] & $Q_{C 1}=\dot{m}_{17} h_{17}-m_{18} h_{18}$ & $\begin{array}{l}\dot{E}_{D, C 1}=\dot{E}_{17}-\dot{E}_{18}- \\
\dot{E}_{C 1}\end{array}$ & [61] \\
\hline & & Solution Exp. Valve 2 & & \\
\hline$\dot{m}_{15}=\dot{m}_{16}$ & [34] & $h_{15}=16$ & $\dot{E}_{D, E X V 2}=\dot{E}_{15}-\dot{E}_{16}$ & [62] \\
\hline & & Evaporator & & \\
\hline$\dot{m}_{9}=\dot{m}_{10}$ & [35] & $Q_{E}=\dot{m}_{10} h_{10}-\dot{m}_{9} h_{9}$ & $\dot{E}_{D, E}=\dot{E}_{9}+\dot{E}_{E}-\dot{E}_{10}$ & [63] \\
\hline & & Absorber & & \\
\hline$\dot{m}_{1}=\dot{m}_{10}+\dot{m}_{6}$ & {$[36]$} & $Q_{A}=\dot{m}_{10} h_{10}+\dot{m}_{6} h_{6}-\dot{m}_{1} h_{1}$ & $\dot{E}_{D, A}=\dot{E}_{10}+\dot{E}_{6}-\dot{E}_{A}-\dot{E}_{1}$ & [64] \\
\hline & & High pressure Pump & & \\
\hline$\dot{m}_{11}=\dot{m}_{12}$ & [37] & $W_{P 2}=\dot{m}_{12}\left(h_{12}-h_{11}\right)$ & $\dot{E}_{D, P 2}=\dot{E}_{12}-\dot{E}_{11}$ & [65] \\
\hline & & Heat exchanger 1 & & \\
\hline $\begin{array}{l}\dot{m}_{12}=\dot{m}_{13} \\
\dot{m}_{14}=\dot{m}_{15}\end{array}$ & [38] & $\begin{array}{l}\dot{m}_{12} h_{12}+\dot{m}_{14} h_{14}=\dot{m}_{13} h_{13}+\quad[52] \\
\dot{m}_{15} h_{15}\end{array}$ & $\begin{array}{c}\dot{E}_{D, H E 1}=\dot{E}_{12}+\dot{E}_{14}-\dot{E}_{13} \\
-\dot{E}_{15}\end{array}$ & [66] \\
\hline & & Refrigerant Exp. Valve 3 & & \\
\hline$\dot{m}_{18}=\dot{m}_{19}$ & [39] & $h_{18}=h_{19}$ & $\dot{E}_{D, E X V 3}=\dot{E}_{18}-\dot{E}_{19}$ & [67] \\
\hline & & Condenser 2 & & \\
\hline$\dot{m}_{7}+\dot{m}_{19}=\dot{m}_{8}$ & [40] & $Q_{C 2}=\dot{m}_{19} h_{19}+\dot{m}_{7} h_{7}-m_{8} h_{8}$ & $\dot{E}_{D, C 2}=\dot{E}_{19}+\dot{E}_{7}-\dot{E}_{8}$ & [68] \\
\hline & & Refrigerant Exp. Valve 4 & & \\
\hline$\dot{m}_{8}=\dot{m}_{9}$ & [41] & $h_{8}=h_{9}$ & $\dot{E}_{D, E X V 4}=\dot{E}_{8}-\dot{E}_{9}$ & [69] \\
\hline & & High pressure generator & & \\
\hline$\dot{m}_{13}=\dot{m}_{14}+\dot{m}_{17}$ & [42] & $\begin{array}{c}Q_{H P G}=\dot{m}_{14} h_{14}+\dot{m}_{17} h_{17} \\
-\dot{m}_{13} h_{13}\end{array}$ & $\dot{E}_{H P G}=\dot{E}_{17}+\dot{E}_{14}-\dot{E}_{13}$ & [70] \\
\hline & & Overall cycle & & \\
\hline & & $C O P=\dot{Q}_{E} /\left(W_{P, t o t}+\dot{Q}_{H P G}\right)$ & $E C O P=\dot{E}_{E} /\left(W_{P, t o t}+\dot{E}_{H P G}\right)$ & [72] \\
\hline
\end{tabular}




\section{Model verification}

In this study, the software used for modeling is the engineering equation solver (EES). In order to verify the present model, the results from this model have been compared with simulation data available from literature of Rabi Karaali [19] and ASHRAE [2]. Input data from literature is given in the following tables:

Table 3. Input data of single absorption system according to ASHRAE [2].

\begin{tabular}{|lc|cc|}
\hline \multicolumn{1}{|c|}{ Parameter } & & \multicolumn{2}{c|}{ Value } \\
\hline Cooling load & $\mathrm{Q}_{\mathrm{E}}$ & 2148 & $\mathrm{~kW}$ \\
\hline Generator temperature & $\mathrm{T}_{\mathrm{G}}$ & 103.5 & ${ }^{\circ} \mathrm{C}$ \\
\hline Evaporator temperature & $\mathrm{T}_{\mathrm{E}}$ & 1.8 & ${ }^{\circ} \mathrm{C}$ \\
\hline Condenser temperature & $\mathrm{T}_{\mathrm{C}}$ & 46.2 & ${ }^{\circ} \mathrm{C}$ \\
\hline Absorber temperature & $\mathrm{T}_{\mathrm{A}}$ & 40.7 & ${ }^{\circ} \mathrm{C}$ \\
\hline Heat exchanger effectiveness & $\varepsilon_{\mathrm{HE}}$ & 70 & $\%$ \\
\hline Pump isentropic efficiency & $\eta_{\mathrm{p}}$ & 95 & $\%$ \\
\hline
\end{tabular}

Table 4. Input data of double absorption system according to ASHRAE [2].

\begin{tabular}{|lc|cc|}
\hline \multicolumn{2}{|c|}{ Parameter } & & \multicolumn{2}{c|}{ Value } \\
\hline Cooling load & $\mathrm{Q}_{\mathrm{E}}$ & 1760 & $\mathrm{~kW}$ \\
\hline Generator temperature & $\mathrm{T}_{\mathrm{G}}$ & 170.7 & ${ }^{\circ} \mathrm{C}$ \\
\hline Evaporator temperature & $\mathrm{T}_{\mathrm{E}}$ & 5.1 & ${ }^{\circ} \mathrm{C}$ \\
\hline Condenser temperature & $\mathrm{T}_{\mathrm{C}}$ & 42.4 & ${ }^{\circ} \mathrm{C}$ \\
\hline Absorber temperature & $\mathrm{T}_{\mathrm{A}}$ & 42.4 & ${ }^{\circ} \mathrm{C}$ \\
\hline Heat exchanger effectiveness & $\varepsilon_{\mathrm{HE}}$ & 70 & $\%$ \\
\hline Pump isentropic efficiency & $\eta_{\mathrm{p}}$ & 95 & $\%$ \\
\hline
\end{tabular}

From comparison it is observed that agreement between two models is satisfactory and data of comparison has been presented in the following tables:-

Table 5. SVARS verification.

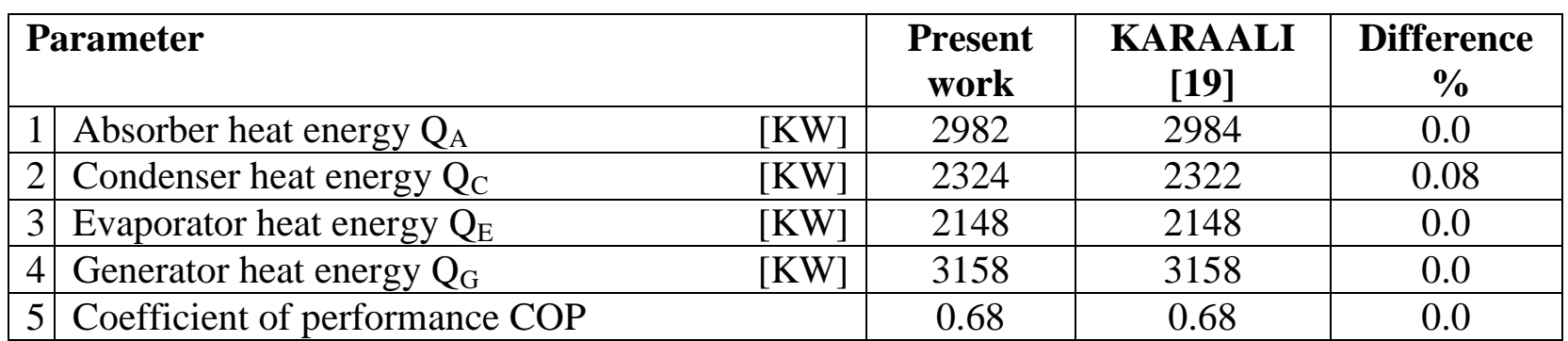

Table 6. DVARS verification.

\begin{tabular}{|c|c|c|c|c|c|}
\hline \multicolumn{3}{|c|}{ Parameter } & Present & ASHRAE & Difference \\
\hline 1 & Absorber heat energy $Q_{A}$ & {$[\mathrm{KW}]$} & 2333 & 2328 & 0.21 \\
\hline 2 & Condenser_1 heat energy $\mathrm{Q}_{\mathrm{C} 1}$ & [KW] & 1026 & 1023 & 0.29 \\
\hline 3 & Condenser_2 heat energy $\mathrm{Q}_{\mathrm{C} 2}$ & [KW] & 902.3 & 905 & 0.29 \\
\hline 4 & Evaporator heat energy $\mathrm{Q}_{\mathrm{E}}$ & [KW] & 1760 & 1760 & 0.0 \\
\hline 5 & High pressure generator heat energy $\mathrm{Q}_{\mathrm{HPG}}$ & {$[\mathrm{KW}]$} & 1475 & 1472 & 0.2 \\
\hline 6 & Low pressure generator heat energy $\mathrm{Q}_{\mathrm{LPG}}$ & [KW] & 1026 & 1023 & 0.29 \\
\hline
\end{tabular}




\section{Results \& discussion}

For this study the selected range of application temperature is from $10^{\circ} \mathrm{c}$ to $20^{\circ} \mathrm{c} \&$ selected range of cooling medium temperature is from $30^{\circ} \mathrm{c}$ to $45^{\circ} \mathrm{c}$ because it depends on atmospheric conditions of the selected region. These assumptions are valid for both single and double absorption cycles.

\subsection{Generator minimum temperature.}

Simulation has been carried out to determine the cut off temperature with selected range of application and cooling medium temperatures.

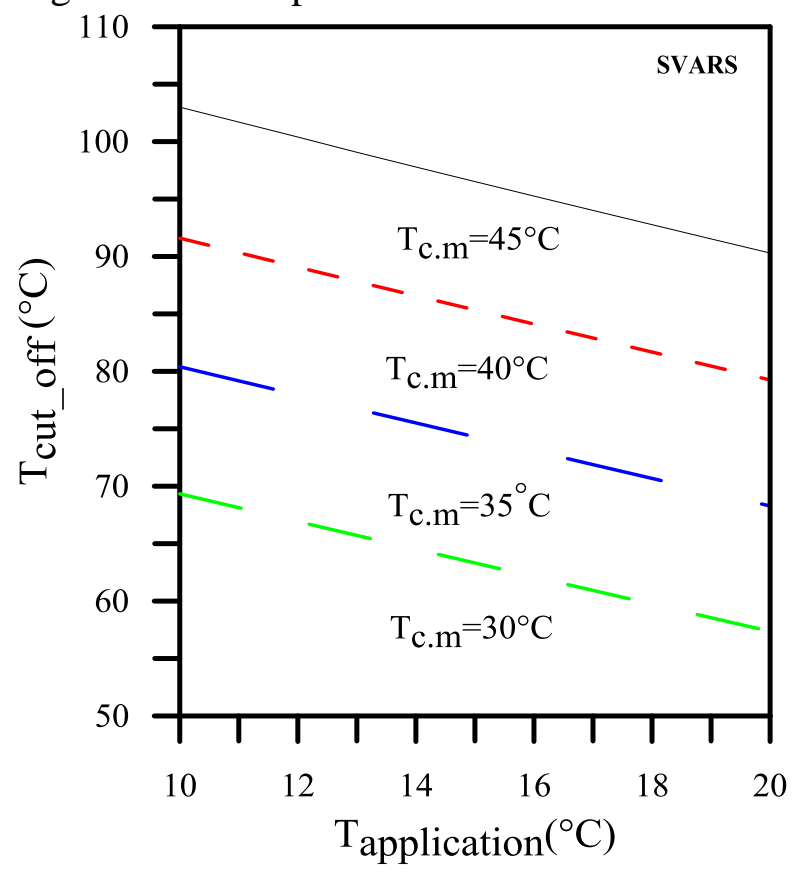

Fig.3 Variation of cut off temperature with application temperature

Fig.3 shows variation of minimum generator temperature with evaporator, absorber and condenser temperature. It is observed that required cut off temperature (min. generator temperature) decreases with evaporator temperature $\left(T_{\text {application }}-\Delta \mathrm{T}\right)$ because mass concentration of water refrigerant in solution increases with evaporator temperature, it causes to lower the cut off temperature of the solution. It is also found that required minimum generator temperature increases with increase in condenser and absorber temperature $\left(\mathrm{T}_{\text {cooling medium }}-\Delta \mathrm{T}\right)$ because as the temperature of condenser and absorber increases, mass concentration of $\mathrm{LiBr}$ in solution increases contributing the higher cut off temperature.

\subsection{Effect of heat source temperature.}

From fig. 4 it's shown that variation of COP of the system increase with increasing the heat source temperature up to certain value then a slight variation is observed. Increasing heat source temperature means higher generator temperature which cause strong solution concentration increase hence mass flow rate of both weak \& strong solution to decrease while the refrigerant mass flow rate remains constant . 
Enthalpy of super-heated refrigerant marginally increases with generator temperature increase while enthalpy of both weak and strong solution increases rapidly. From generator heat load equation it is observed that the generator load $\mathrm{Q}_{\mathrm{G}}$ is decreased, since the cooling load $\mathrm{Q}_{\mathrm{E}}$ is constant hence the COP increases with the increase of the heat source temperature.

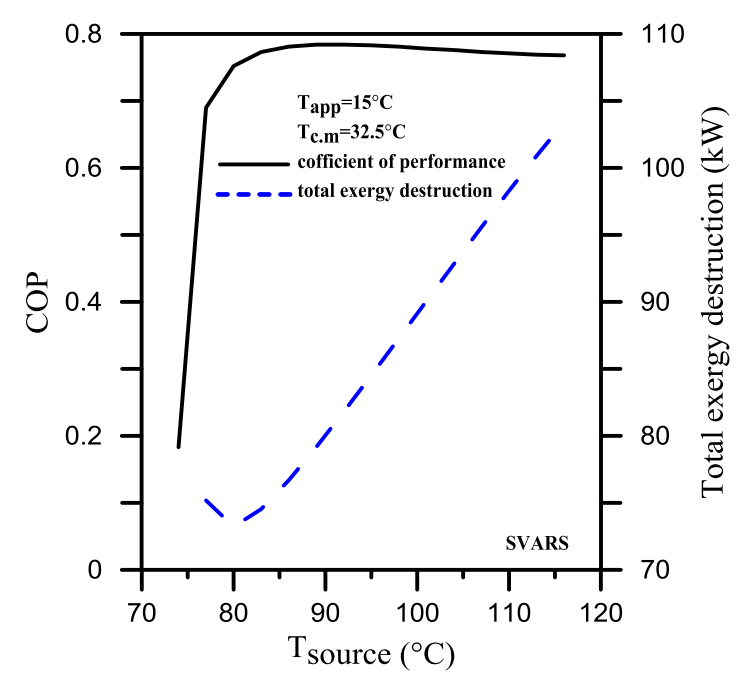

Fig.4 Variation of COP \& total exergy destruction at different heat source temperatures(SVARS).

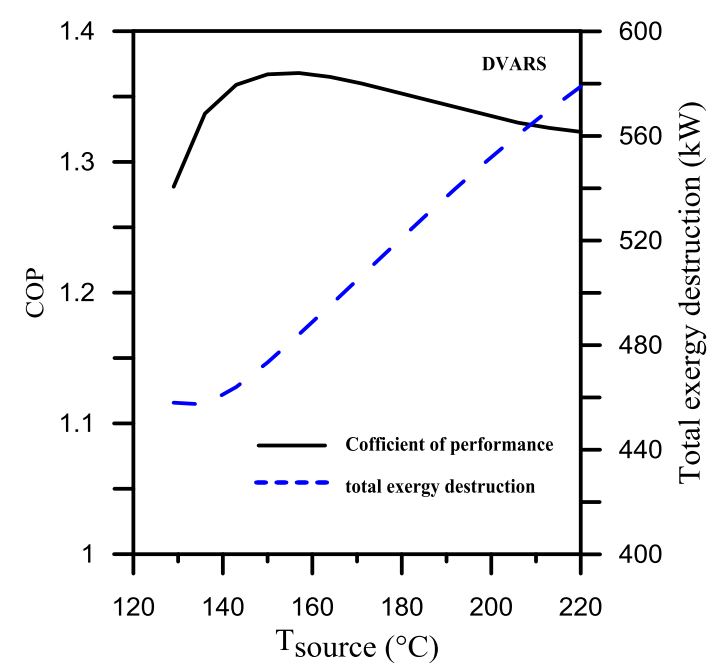

Fig.6 Variation of COP \& total exergy destruction at different heat source temperatures(DVARS).

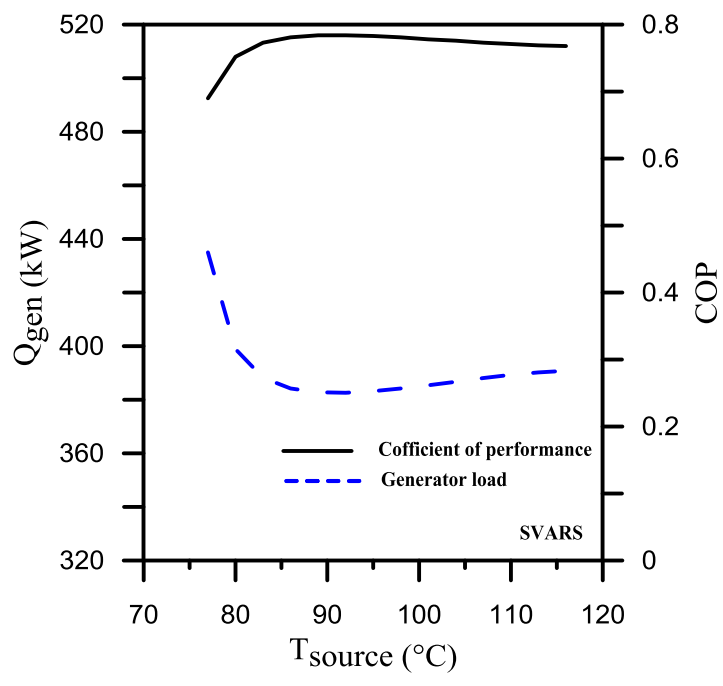

Fig.5 Variation of COP \& generator load at different heat source temperatures (SVARS).

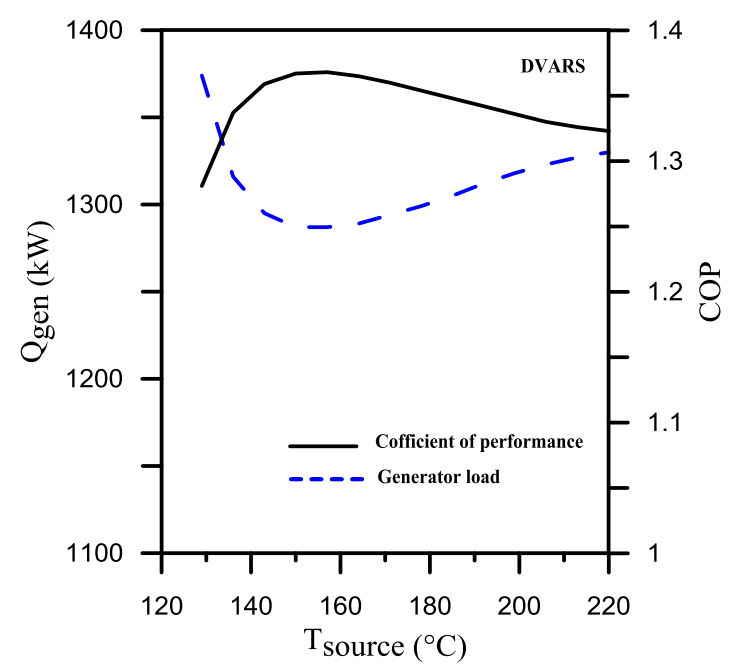

Fig.7 Variation of COP \& generator load at different heat source temperatures (DVARS).

From fig. 4 it is also found that total exergy destruction of system increases with the increase of the heat source temperature. This can be understood by Fig. 5 it is observed that exergy destruction in absorber, condenser and generator increases with increasing generator temperature while in solution heat exchanger it decreases. It is clear that with 
increasing generator temperature total exergy destruction of system increases rapidly so it is necessary to optimize the generator temperature for minimization of exergy destruction of system.
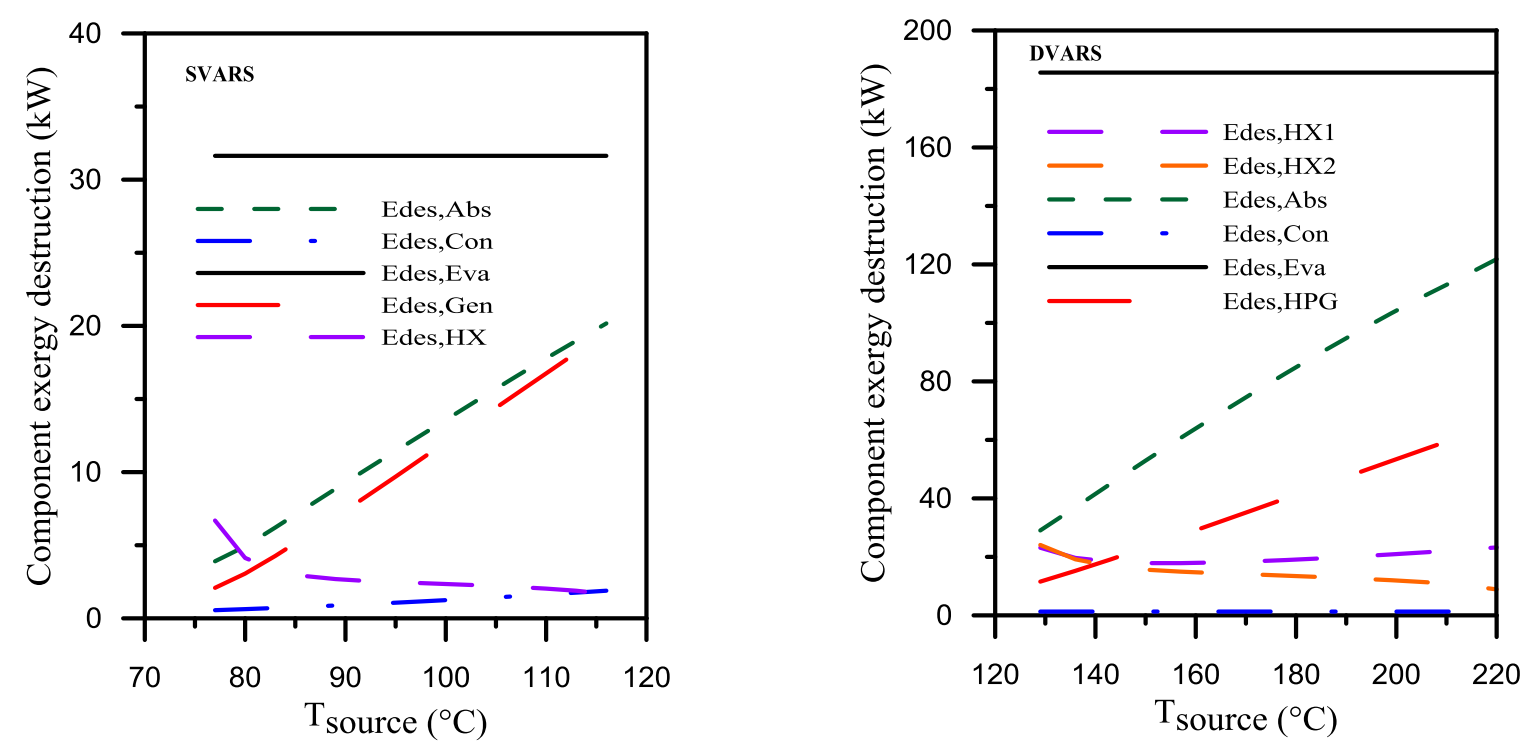

Fig.8 Exergy destruction of system components at different heat source temperatures.

\subsection{Optimum heat source temperature.}

From fig.6 it's shown that variation of optimum heat source temperature corresponding to maximum COP. It is observed that COP increases with increasing application temperature while it decreases with increasing cooling medium temperature. Maximum COP is obtained at higher evaporator temperature \& lower condenser temperature.
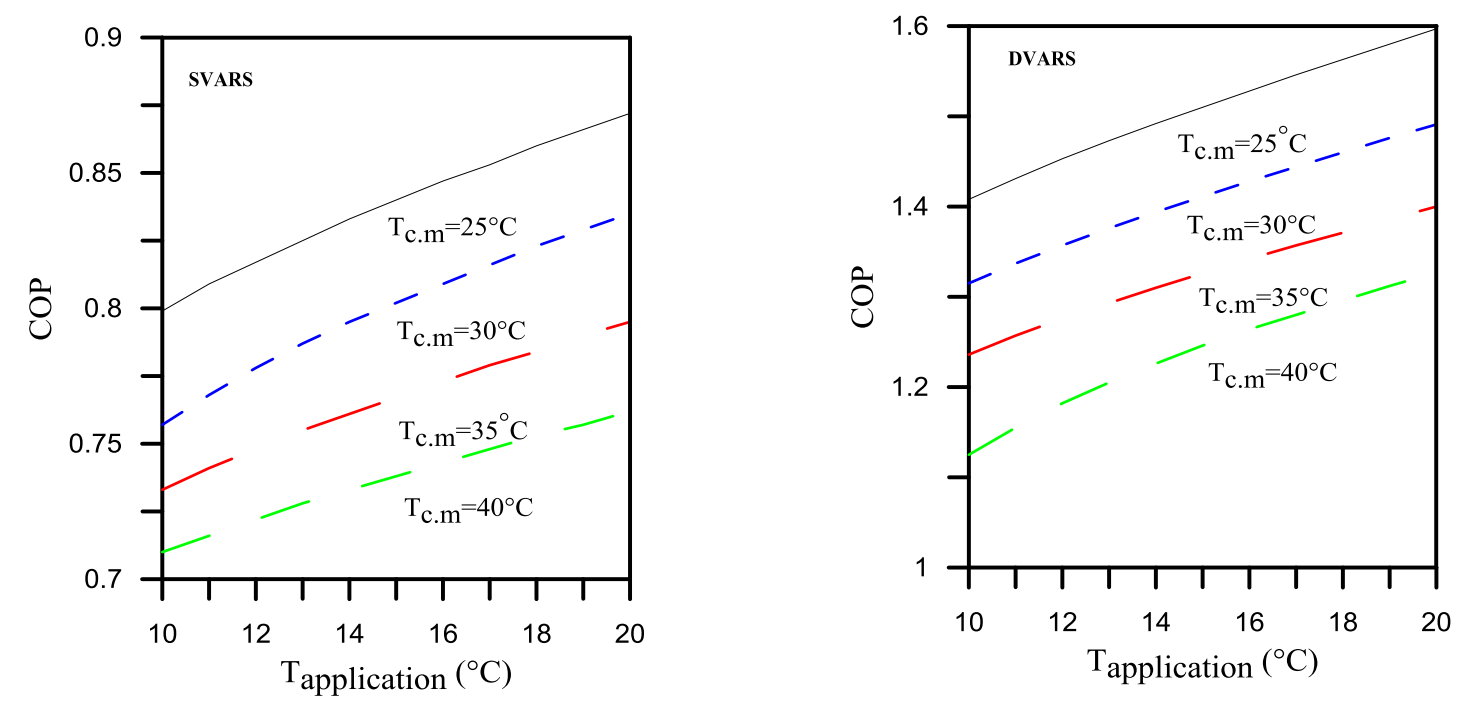

Fig.9 Variation of COP of system with application temperature at different cooling medium temperatures.

From fig.7 it's shown that variation of the optimum heat source temperature corresponding to minimum exergy destruction. It is observed that minimum exergy destruction rate 
decreases with the increase in application temperature because as evaporator temperature increases difference between refrigerant and ambient temperature decreases hence system subjected to lower exergy destruction.

As cooling medium temperature increases, temperature difference between refrigerant and outer circuit cooling medium increases hence system subjected to higher exergy destruction. It is observed that minimum exergy destruction is at lower condenser and higher evaporator temperature.
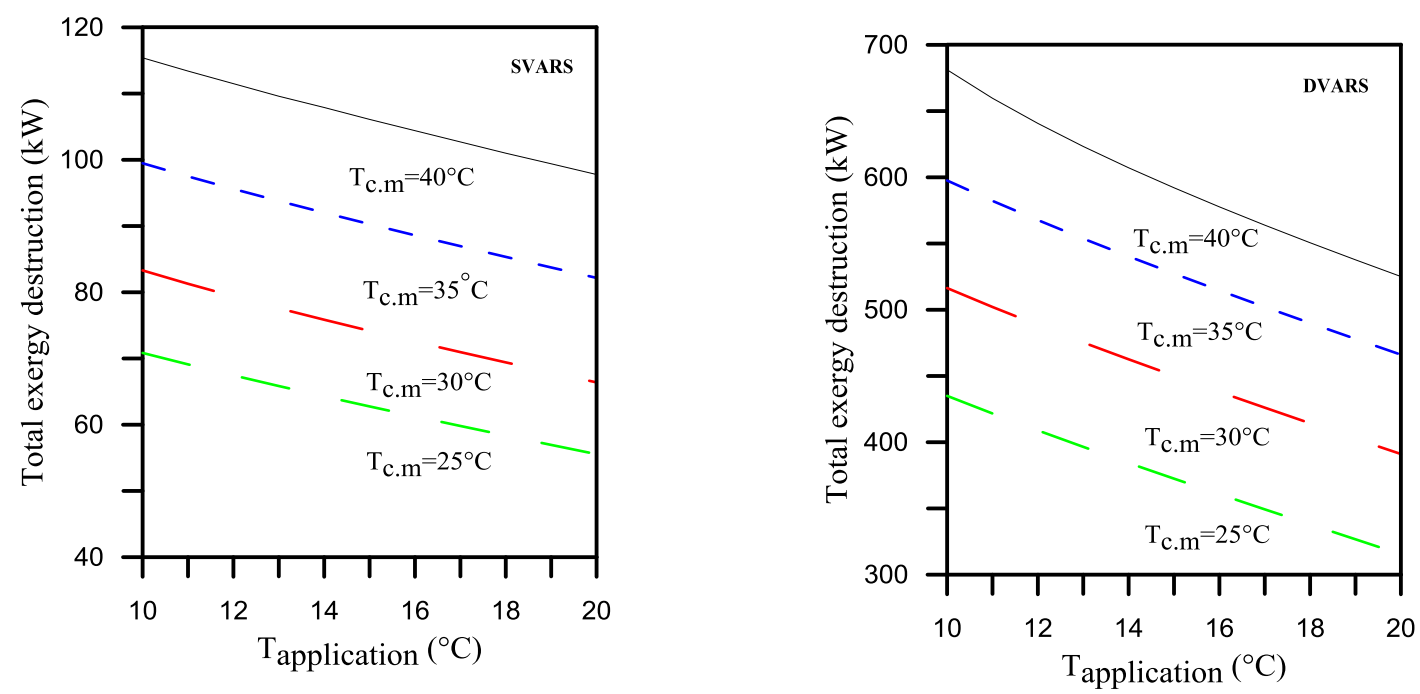

Fig.10 Variation of total exergy destruction with application temperature at different cooling medium temperatures.

From fig. 8 it's shown that variation of exergetic coefficient of performance ECOP of the system decrease with increasing the application temperature. It is also found that required minimum ECOP is by increasing both condenser and evaporator temperatures.

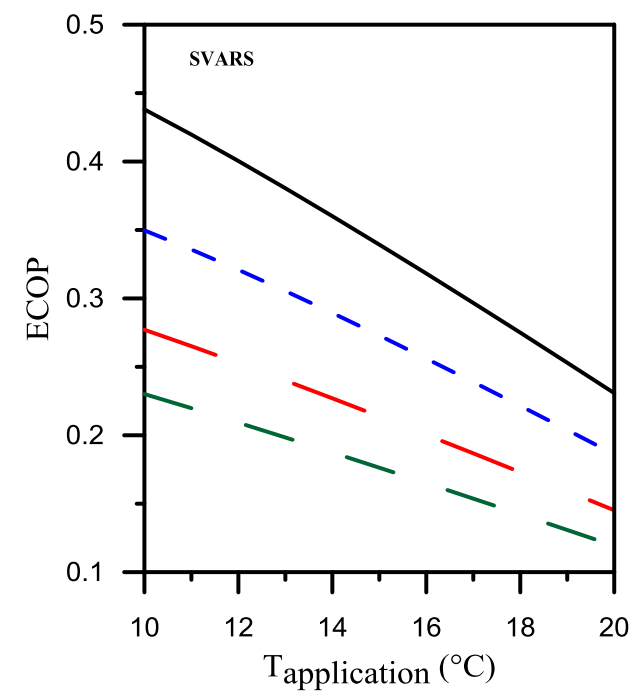

Fig.11 Variation of ECOP different application temperatures (SVARS).

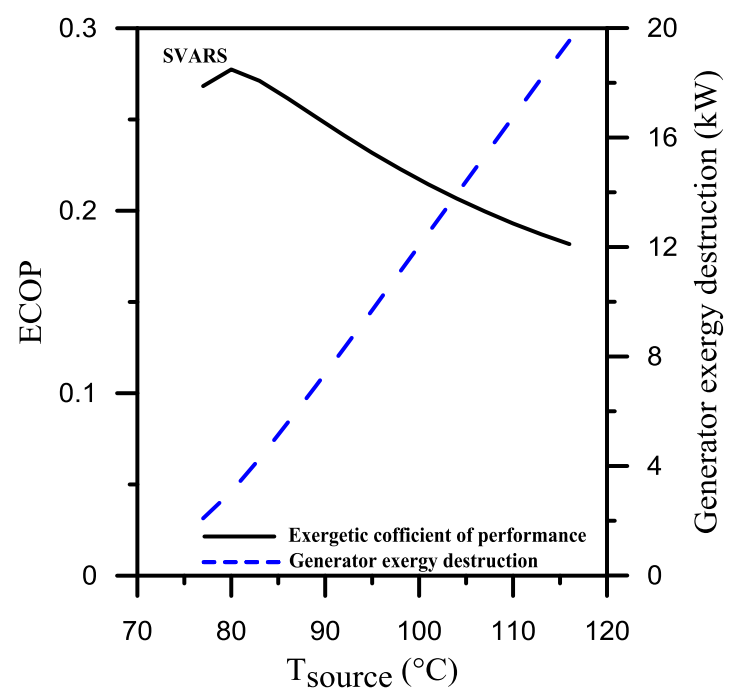

Fig.12 Variation of ECOP \& generator exergy at different heat source temperatures (SVARS). 


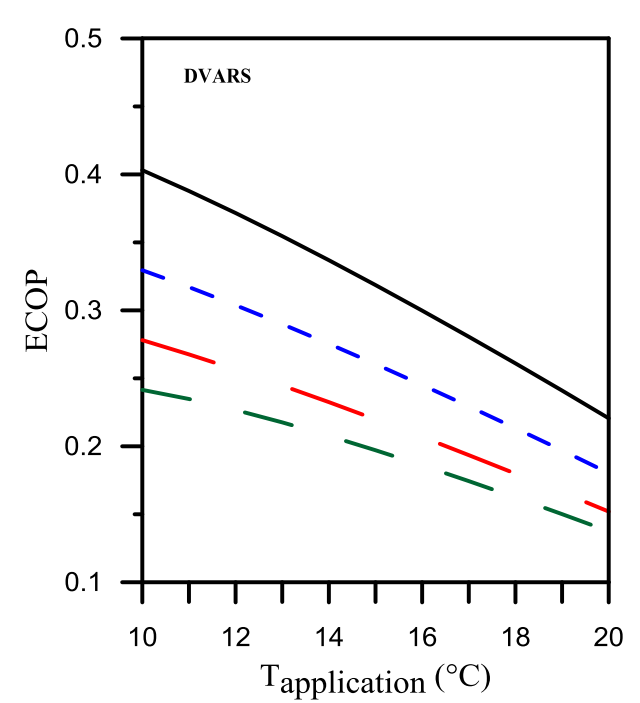

Fig.13 Variation of ECOP at different application temperatures(DVARS).

\section{System optimization}

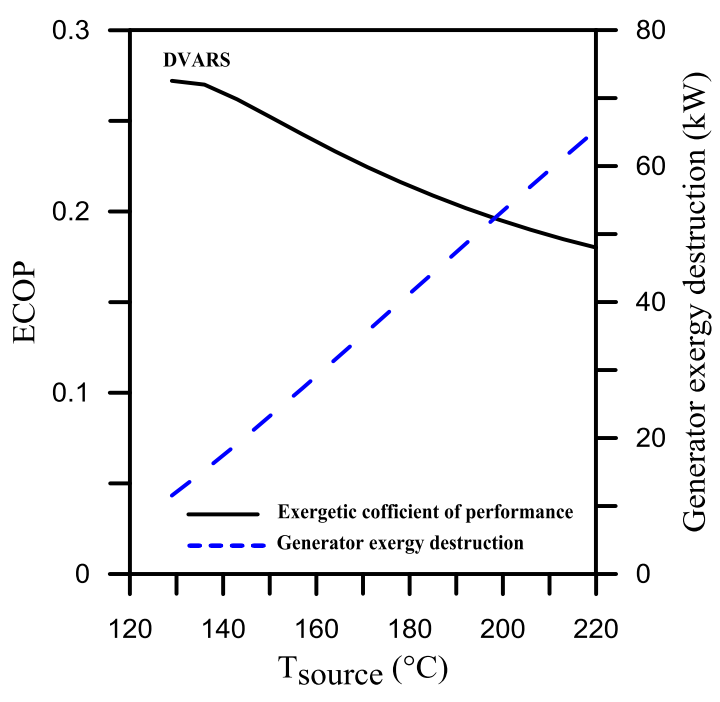

Fig.14 Variation of ECOP \& generator exergy at different heat source temperatures (DVARS).

From Fig.6 it is concluded that optimized COP increases with increasing evaporator temperature while it decreases with increasing condenser temperature. From Fig.8 it is observed that optimized exergy destruction decreases with evaporator temperature while it increases with condenser temperature. Therefore, it is proven that optimum generator temperature for both maximum COP and minimum exergy destruction is strong function of evaporator and condenser temperature. Through this thermodynamic analysis it is also observed that optimum generator temperature corresponding to optimized COP and exergy destruction is not identical.

\subsection{Optimization function for the SVARS.}

Optimum generator temperature corresponding to maximum COP is function of both application temperature $\&$ cooling medium temperature. The optimization function can be expressed using DataFit software [20] as follows:-

$\mathrm{T}_{\mathrm{G} . \mathrm{OPT}}=\left[\left(\mathrm{a} \times \mathrm{T}_{\mathrm{cm}}{ }^{8}\right)+\left(\mathrm{b} \times \mathrm{T}_{\mathrm{cm}}{ }^{7}\right)+\left(\mathrm{c} \times \mathrm{T}_{\mathrm{cm}}{ }^{6}\right)+\left(\mathrm{d} \times \mathrm{T}_{\mathrm{cm}}{ }^{5}\right)+\left(\mathrm{e} \times \mathrm{T}_{\mathrm{cm}}{ }^{4}\right)+\right.$ $\left.\left(\mathrm{f} \times \mathrm{T}_{\mathrm{cm}}{ }^{3}\right)+\left(\mathrm{g} \times \mathrm{T}_{\mathrm{cm}}{ }^{2}\right)+\left(\mathrm{h} \times \mathrm{T}_{\mathrm{cm}}\right)+\mathrm{i}\right] \quad[73]$

Where:-

$\mathrm{T}_{\mathrm{G} . \mathrm{OPT}} \ldots$... Optimum heat source temperature.

$\mathrm{T}_{\mathrm{cm}} \quad \ldots$ Cooling medium temperature from location weather data.

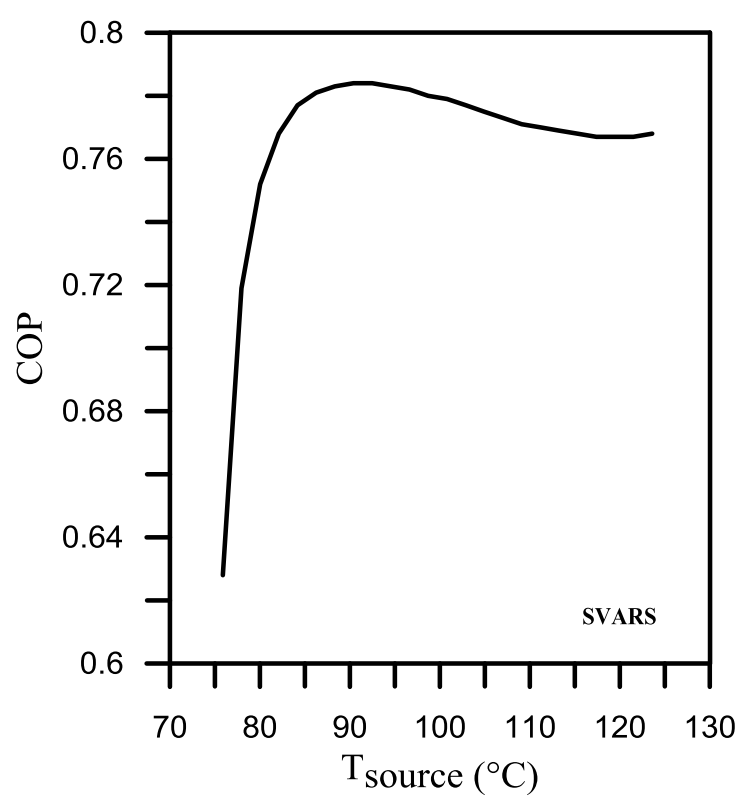

Fig.15 Variation of COP of system with 
heat source temperature (DVARS).

Table 7. Constants values of the single cycle optimization function

\begin{tabular}{|c|c|c|c|c|c|}
\hline a & $-7.289118796 \mathrm{E}-008$ & $\mathrm{D}$ & 0.100166743 & $\mathrm{~g}$ & -373.6621577 \\
\hline b & $1.767572504 \mathrm{E}-005$ & $\mathrm{E}$ & 3.190068852 & $\mathrm{~h}$ & -2113.292436 \\
\hline c & -0.001807307719 & F & 55.35086249 & $\mathrm{i}$ & 33988.6617 \\
\hline
\end{tabular}

\subsection{Optimization function for the DVARS}

Optimum generator temperature corresponding to maximum COP is function of both application temperature $\&$ cooling medium temperature. The optimization function can be expressed using DataFit software [20] as follows:-

$\mathrm{T}_{\mathrm{G} . \mathrm{OPT}}=$

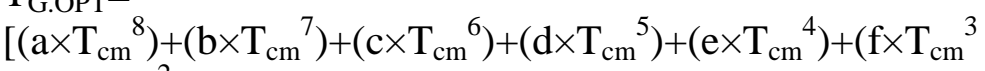
)$\left.+\left(\mathrm{g} \times \mathrm{T}_{\mathrm{cm}}^{2}\right)+\left(\mathrm{h} \times \mathrm{T}_{\mathrm{cm}}\right)+\mathrm{i}\right] \quad[74]$

Where:-

$\mathrm{T}_{\mathrm{G} . \mathrm{OPT}} \ldots$ Optimum generator temperature

$\mathrm{T}_{\mathrm{cm}} \quad \ldots$ Cooling medium temperature from location weather data.

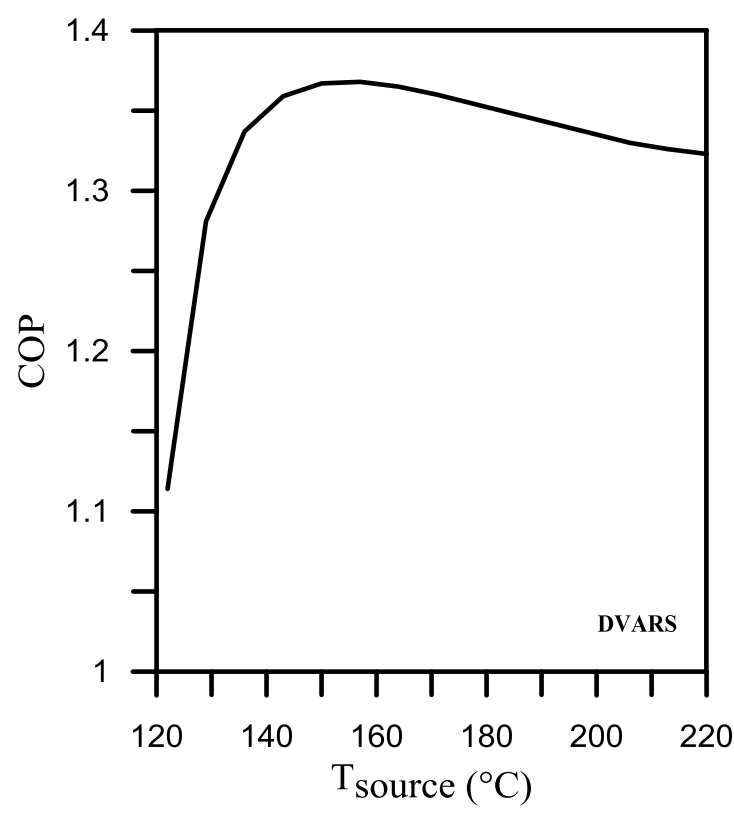

Fig.16 Variation of COP of system at different heat source temperatures (DVARS).

Table 8. Constants values of the double cycle optimization function

\begin{tabular}{|c|c|c|c|c|c|}
\hline a & $-4.144567691 \mathrm{E}-007$ & $\mathrm{D}$ & 0.8389046313 & $\mathrm{~g}$ & -11804.36869 \\
\hline b & 0.0001115983246 & $\mathrm{E}$ & -33.16073355 & $\mathrm{~h}$ & 90923.74712 \\
\hline c & -0.01292974685 & $\mathrm{~F}$ & 810.8597299 & $\mathrm{i}$ & -264988.4747 \\
\hline
\end{tabular}




\section{Conclusion}

In this paper, a simulation of both single and double $\mathrm{LiBr}-\mathrm{H}_{2} \mathrm{O}$ VARS is presented in order to study the influence of operating temperature on system performance, an optimization function is conducted to purpose the best operating generator temperature that yields the best system performance from the COP point of view. Based on the reported results, the following conclusions are drawn:

- The simulation shows that minimum generator temperature (cut off) of system increases about $2.2^{\circ} \mathrm{C}$ with $1^{\circ} \mathrm{C}$ increase in the cooling medium temperature while it decreases about $1.2^{\circ} \mathrm{C}$ with $1^{\circ} \mathrm{C}$ increase in the application temperature.

- It is also observed that COP of system increase with heat source temperature up to about $75 \%$ then a very negligible variation is observed while exergy destruction rate of system increases continuously with the increase of heat source temperature.

- Most of the irreversibility occurred in the evaporator and in the absorber which is about $70 \%$ of the total irreversibility. To improve the performance and the working conditions of the cycle better design and improving of these two components is essential.

- It is proven that optimum generator temperature for both maximum COP and minimum exergy destruction is strong function of evaporator and condenser temperature.

- Optimum generator temperature increases about $2.2^{\circ} \mathrm{C}$ with $11^{\circ} \mathrm{C}$ increase in the condenser temperature and decreases about $1.2^{\circ} \mathrm{C}$ with $1^{\circ} \mathrm{C}$ increase in the evaporator temperature.

- Optimization of LiBr-H2O VARS is carried out either using the maximum COP approach or the minimum exergy destruction approach and results are not identical, so we have to prefer one over the other. 


\section{References}

[1] P.Srikhirin, S.Aphornratana, S.Chungpaibulpatana A review of absorption refrigeration technologies. Renewable and sustainable energy reviews 2001; 5:343-72.

[2] ASHRAE Fundamentals Handbook, 2001 Chapter 1.Thermodynamics and refrigeration cycles.

[3] L.A. Domínguez-Inzunza, M. Sandoval-Reyes, J.A. Hernández-Magallanes, W. Rivera, "Comparison of the performance of single-effect, half-effect, double-effect in series and inverse absorption cooling systems operating with the mixture $\mathrm{H} 2 \mathrm{O} / \mathrm{LiBr}$ ", Energy Procedia 57, 2534-2543, 2014.

[4] M. Izquierdo, A. González-Gil, E. Palacios, "Solar-powered single-and double-effect directly air cooled $\mathrm{LiBr}-\mathrm{H} 2 \mathrm{O}$ absorption prototype built as a single unit", Applied Energy 130, 7-19, 2014.

[5] G.A. Florides, S.A. Kalogirou, S.A. Tassou, L.C. Wrobel. Modelling, simulation and warming impact assessment of a domestic size absorption solar cooling system. Applied Thermal Engineering 2002; 22: 1313-25.

[6] S.B. Riffat, G. Qiu. Comparative investigation of thermoelectric air conditioners versus vapor compression and absorption air-conditioners. Applied Thermal Engineering 2004; 24: 1979-93.

[7] A. Şencan, K.A. Yakut, S.A. Kalogirou. Exergy analysis of lithium bromide/water absorption systems. Renewable energy 2005; 30: 645-657.

[8] A. Myat, K. Thu, Y.D. Kim, A. Chakraborty, W.G. Chun, K.C. Ng. A second law analysis and entropy generation minimization of an absorption chiller. Applied Thermal Engineering 2011; 31: 2405-13.

[9] O. Kaynakli, R. Yamankaradeniz. Thermodynamic analysis of absorption refrigeration system based on entropy. Current science 2009;92: 472-79.

[10] S. Aprhornratana, I. W. Eames. Thermodynamic analysis of absorption refrigeration cycles using the second law of thermodynamics method, International Journal of Refrigeration 1995;18:244-52.

[11] M. Kilic, O. Kaynakli. Second law-based thermodynamic analysis of water-lithium bromide absorption refrigeration system. Energy 2007; 32:1505-12.

[12] M.M. Talbi, B. Agnew. Exergy analysis: an absorption refrigerator using lithium bromide and water as the working fluids. Applied Thermal Engineering 2000;20: 619-30.

[13] G. Gutiérrez-Urueta, A. Huicochea, P. Rodríguez-Aumente, W. Rivera. Energy and Exergy Analysis of Water-LiBr Absorption Systems with Adiabatic Absorbers for Heating and Cooling. Energy Procedia 2014;57: 2676-85.

[14] A. Arora, S.C. Kaushik. Theoretical analysis of $\mathrm{LiBr} / \mathrm{H} 2 \mathrm{O}$ absorption refrigeration systems. International Journal of Energy Research 2009;33: 1321-40. 
[15] R. Gomri. Second law comparison of single effect and double effect vapour absorption refrigeration systems. Energy Conversion and Management 2009;50: 1279-87.

[16] J.D. Marcos, M. Izquierdo, E. Palacios. New method for COP optimization in waterand air-cooled single and double effect $\mathrm{LiBr}-$ water absorption machines, International journal of Refrigeration 2011;34: 1348-59.

[17] S.A. Klein, F.L. Alvarado. Engineering equation solver, F-Chart Software, Madison. WI 2017.

[18] B.Pandya, J.Patel, A.Mudgal. Thermodynamic evaluation of generator temperature in LiBr-Water absorption system for optimal performance, International Conference on Recent Advancement in Air Conditioning and Refrigeration, RAAR, Bhubaneswar, India .Elsevier Ltd., 2016.

[19] R. Karaali. Exergy analysis of double effect absorption cycle, international journal of engineering, science \& research technology, IJESRT, 2016.

[20] DataFit version 7.1.44, Okadale Engineering, copyright @ 1995-2001. 